\title{
Students' Engagement in Educational Software: A Comparison between Narrative and Traditional Styles
}

\author{
Mohammed Alameer and Thamer Alhussain
}

\begin{abstract}
This paper presents a survey study that explores the difference between an educational software based on a narrative style and another based on a traditional style in terms of students' engagement. For this investigation, two different questionnaires were distributed to students in two different crucial stages. In the first stage, a questionnaire was given to students to find out information about the stories they are reading in general and their desired story characteristics. An educational software based on both the preferred character and narrative style was developed for the purpose of this study. Then, another questionnaire was distributed to explore students' perceptions about both software styles. It is found that the educational software based on the narrative style better facilitate students' engagement comparing with educational software based on traditional style taken into account the kind of the character and story.
\end{abstract}

Index Terms-Educational software, narrative style, traditional style.

\section{INTRODUCTION}

Providing an interactive educational environment is becoming increasingly important. Visualization, modelling, simulation, and 3D graphics in computer-based applications or educational software are becoming influential tools for teaching various subjects. Educational systems are continuing to increase the use of information technologies, both in terms of hardware and software, for courses taught in schools. However, interaction is one of the most essential principles in designing educational software [1]. The implementation of this principle can be dealt with as an art. It requires an inclusive range of skills which include an understanding of the nature of students, software engineering, the current design basics and learning methodologies in education, and knowledge of the aesthetic design principles for the multimedia application interfaces. This will create an interactive educational environment that will ensure the students' engagement [1]. The objective of educational software is to effectively enhance the knowledge of students.

This paper compares the use of educational software based on a narrative style and another based on a traditional style in terms of students' engagement. It discusses a survey study exploring the perceptions of sixth elementary grade students regarding the use of narrative and traditional educational software in learning English as a foreign language.

Manuscript received September 13, 2014; revised November 15, 2014.

M. Alameer is with the Ministry of Higher Education, Riyadh, Saudi Arabia (e-mail: mameer@mohe.gov.sa).

T. Alhussain is with Saudi Electronic University, Riyadh, Saudi Arabia (e-mail: talhussain@seu.edu.sa).

\section{LITERETURE REVIEW}

\section{A. Educational Software}

MacFarlane et al. present the general objective of educational software for students as providing "an engaging learning environment and keeping children's attention by providing fun" [2]. Fun, particularly with children, is normally achieved through games. However, adopting Information technology into education has its own danger; that is, by being perceived as fun and entertainment, learning devaluates considerably [2]. According to Andrea et al. [3], Information technology can provide a considerable high-level of learning and it is helpful in the development of decisive thinking skills, analysis, and systematic inquisition. However, computers alone do not guarantee their usefulness. They should promote active engagement, group participation, and recurrent interaction and feedback. Since the critical feature of various learning environment centres on the role of teachers, educational software should "foster a move from teacher centred to learner centred pedagogies" [4].

In the development of educational software, education experts have acquired more familiarity with computer-based technology. Consequently, there has been a transformation from the behaviourist paradigm and artificial intelligence approach to a pedagogical constructivist view. In the early years, the behaviourist paradigm dominated the idea of computer-assisted learning and later, during the 1980s, artificial intelligence emerged and promoted the concept of intellectual tutoring system. All these systems attempted to develop suitable and significant models for the learners and teachers, but they seemed to fail [4] Developing realistic learner and teacher models has been persistent and this is the reason why the artificial intelligence method has been terminated [4]. Educational experts believe that constructivism is far better since it offers a considerable number of ways to enhance learning realistically. Many published articles focus on better educational software and better learning anticipate constructivism as its vehicle [4].

\section{B. Computer-Assisted Instruction (CAI) and Computer-Assisted Language Learning (CALL)}

Computers have developed rapidly over the past quarter century in becoming more powerful, faster, cheaper, smaller, easier to use, and more convenient. Throughout fifty years of use and application in education, computers have undergone significant shifts. Although computer usage was significantly increasing, it was limited to few applications of drill-and-practice, tutorial Computer-Assisted Instruction, and games [5]. Through the early uses of computers in classrooms, the focus was on the product of learning 
suggested by behaviourism. Later, however, the focus shifted to the cognitive processes of learning, changing the role of computer programs available to produce a complete computerized learning environment.

Computers began to be used in education in the 1960s with the introduction of computer-assisted instruction (CAI) that was later used for the teaching of most subjects, especially mathematics. Language learning and instruction used the CAI innovation branched out to a technology devoted to the use of computer technology for language learning and teaching named computer-assisted language learning (CALL) or computer aided language learning (CALL), or computer-assisted language instruction (CALI) [6]. This kind of application has been developed, and one of its modern versions is called interactive intelligence.

A computerized learning environment is now often based on multimedia, which involves the integration of text, sounds, still pictures, video, and animation in a single delivery system. The rapid development in information technology caused the production of specialized educational software to be applied with the instruction of most disciplines known as Computer-Assisted-Instruction (CAI). According to Microsoft Computer Dictionary [7], Computer-Assisted-Instruction (CAI) can be defined as "a type of educational program designed to serve as a teaching tool. CAI programs use tutorials, drills, and question-and-answer sessions to present a topic and to test the student's comprehension. CAI programs are excellent aids for presenting factual material and for allowing students to pace their learning speed. Subjects and complexity range from beginning to advance in science, languages, history, computer studies, and specialized topics".

The rapid technological advances of the 1980s raised both the expectancy and needs placed on the computer as a sophisticated teaching and learning tool, especially with the advent of the Internet in 1995. This development increased interest in using computers for teaching and learning, most predominately the teaching of languages; multimedia, hypermedia and the Internet have changed the role of the computers in general, especially in language instruction.

Throughout its gradual development, CALL has undergone three distinct phases, the behaviouristic CALL, the communicative CALL, and the integrative CALL. All three phases went through slow application and uneven acceptance subsuming the old phase with the new one [8].

\section{The Concept of Narrative}

It is believed that narrative provides the structure and consistency required to attain a higher level of learning [9]. Providing a story is considered a form of teaching; teaching of the story enhances connection with others, develops listening skills, and the students gain language skills, thinking and creation, in addition to values and morals. Furthermore, teaching through story plays a big role in forming the students' personalities [10].

After the revolution of technology, many human art forms have developed into electronic learning. Nowadays, narratives can be found in educational software. This is a writing, drama or cinema shown as radio or television programs that narrate details of incidents or an act or course of events. Although there are varying definitions of the narrative, all of them seem to denote 'effective' conversational story telling. Norrick [11] states that one "conversationalist becomes the storyteller, while the others become listeners". The teller introduces the story to acquire the listeners' curiosity, secure control of the floor, and guarantee an acceptance. The narrator must outline memorized materials into a spoken presentation designed for the present situation. Moreover, even with listeners disrupting or attempting to be the co-storyteller, the story recipients can clearly recognize and assess the story with corresponding stories of their own. The narrative therefore boosts customary or everyday conversation to intensify the listeners' concentration and promote enhanced comprehension of the story or the subject matter in focus.

\section{CONDUCT OF THE STUdY}

The review of the current literature on educational software guided our research and the literature on methods available for an exploratory study. Given the exploratory nature of the study and since the questionnaires is an effective method to explore people's attitudes and opinions regarding particular issues [12], it was used in the two different stages of this research. In the first stage, a questionnaire was given to students to find out information about the stories they are reading in general and their desired story characteristics including the kind of story and characters they preferred. An educational software based on both the preferred character and narrative style was developed for the purpose of this study. In the second stage, two educational software programs, 1) based on narrative style, and 2) based on traditional style, were used by the students. Then, a questionnaire was distributed to investigate the narrative educational software's effectiveness in teaching English as a foreign language for sixth elementary grade students compared with the traditional.

With regard to location and participants, two elementary schools in Riyadh in the Kingdom of Saudi Arabia had been chosen. These schools were chosen because of the availability of a computer lab in the schools. Recently, Saudi Arabia, are doing their best to implement in their schools the teaching of English as a foreign language in addition to their mother tongue, so that citizens of the country can contact the world and be familiar with all the new events in the world. Accordingly, the Ministry of Education decided to teach English as a foreign language in elementary grades to begin from the sixth grade beginning from 2004.

In the first questionnaire, 66 students including boys and girls were selected from the total number (136) of sixth grade students in both schools. For the second questionnaire, 86 students including boys and girls participated in this stage.

\section{FINDINGS}

\section{A. First Questionnaire}

The first questionnaire was given to help determine the students' preferred characters and narrative style. The results 
are given in the following sections.

Table I shows the distribution of the sample according to students' responses to reading stories outside schools, listening to the stories, watching TV stories and writing stories outside classroom.

TABLE I: DISTRIBUTION OF THE SAMPLE ACCORDING TO THEIR SCORES

\begin{tabular}{|c|c|c|c|c|c|c|c|}
\hline \multirow[t]{2}{*}{ Questions } & $\begin{array}{l}\text { Never } \\
1\end{array}$ & 2 & 3 & 4 & A lot of 5 & Mean & \multirow[t]{2}{*}{ S.D } \\
\hline & $\%$ & $\%$ & $\%$ & $\%$ & $\%$ & & \\
\hline Do you like reading stories outside school? & 4.55 & 16.67 & $\begin{array}{l}18.1 \\
8\end{array}$ & $\begin{array}{l}30.3 \\
0\end{array}$ & 30.30 & 3.65 & $\begin{array}{l}1.2 \\
1\end{array}$ \\
\hline Do you like listening to stories? & 3.03 & 3.03 & 9.09 & $\begin{array}{l}12.1 \\
2\end{array}$ & 72.73 & 4.48 & $\begin{array}{l}1.0 \\
0\end{array}$ \\
\hline Do you like watching TV stories? & 6.06 & 3.03 & $\begin{array}{l}12.1 \\
2\end{array}$ & 1.52 & 63.64 & 4.27 & $\begin{array}{l}1.1 \\
7\end{array}$ \\
\hline Do you like writing stories outside your classroom? & 28.79 & 13.64 & $\begin{array}{l}21.2 \\
1\end{array}$ & $\begin{array}{l}19.7 \\
0\end{array}$ & 16.67 & 2.82 & $\begin{array}{l}1.4 \\
7\end{array}$ \\
\hline
\end{tabular}

The results reveal that the item "do you like listening to stories?" has the largest mean (4.48) while the item "do you like writing stories outside your classroom?" is lowest (mean=2.82).

It is found that $30.3 \%$ of the sample like reading stories outside school a lot, while $4.55 \%$ of them they never like reading stories outside school.

$72.73 \%$ of the sample like listening to stories, while $3.03 \%$ of them they never like listening to stories.

$63.64 \%$ of the sample like watching TV stories, while $6.06 \%$ of them they never like it.

$16.67 \%$ of the sample like writing stories outside their classroom while $28.79 \%$ of them they never like it.

TABLE II: DisTRIBUTION OF THE SAMPLE ACCORDING TO HOW MUCH CAN YOU REMEMBER FROM A STORY THAT YOU HAVE WATCHED

\begin{tabular}{|c|c|c|}
\hline Question & & $\begin{array}{l}\text { How much can you remember from a story } \\
\text { that you have watched }\end{array}$ \\
\hline \multirow{2}{*}{$\begin{array}{l}\text { Nothing } \\
1\end{array}$} & No & 7 \\
\hline & $\%$ & 10.61 \\
\hline \multirow[t]{2}{*}{2} & No & 4 \\
\hline & $\%$ & 6.06 \\
\hline \multirow[t]{2}{*}{3} & No & 10 \\
\hline & $\%$ & 15.15 \\
\hline \multirow[t]{2}{*}{4} & No & 20 \\
\hline & $\%$ & 30.30 \\
\hline \multirow{2}{*}{$\begin{array}{l}\text { A lot } \\
5\end{array}$} & No & 25 \\
\hline & $\%$ & 37.88 \\
\hline Mean & 3.79 & \\
\hline S.D & 1.31 & \\
\hline
\end{tabular}

Next, we will consider the question of how much the students remember from a story that they have watched. Table II shows that $37.88 \%$ of the study sample remembers a lot from a story that they had watched, while $10.61 \%$ of them say that they never remember anything from a story that they had watched. Moreover, responses 4 and 5, together, account for $68.18 \%$ of the sample. This suggests that most students believe that stories help them remember things.

The purpose of the next question was to find the kind of story which the students like more. Table III shows that $40.9 \%$ like funny stories, $36.4 \%$ of them like adventure stories, $12.1 \%$ of them like family and friends' stories and $10.6 \%$ liked historical stories.

TABLE III: DisTRIBUTION OF THE SAMPLE ACCORDING TO WHAT KIND OF STORY DO YOU LIKE

\begin{tabular}{lll}
\multicolumn{3}{c}{ STORY DO YOU LIKE } \\
\hline \hline Adventure & No & $\%$ \\
Historical & 24 & 36.4 \\
Family and friends & 7 & 10.6 \\
Funny & 8 & 12.1 \\
Total & 27 & 40.9 \\
\hline \hline
\end{tabular}

The objective of the final question was to find out the preferred character for the students from 12 suggested characters. Students were given 12 characters and asked to give them in order of preference. Table IV shows the distribution of the sample for the 12 possible rankings of each character.

The results show the following:

- The car comes in first position with an average ranking of 2.71

- The monster comes in second position with an average ranking of 3.79

- The detective comes in third position with an average ranking of 4.32

- The pencil comes in fourth position with an average ranking of 4.32

- The helicopter comes in fifth position with an average ranking of 6.67

- The turtle comes in sixth position with an average ranking of 6.76

- The boy comes in seven position with an average ranking of 7.27

- The camel comes in eight position with an average ranking of 7.57

- The man comes in nine position with an average ranking of 7.85

- The train comes in tenth position with an average ranking of 8.06

- The bear comes in eleventh position with an average ranking of 8.12

- The carrot comes in twelfth position with an average ranking of 8.83

\section{A. Second Questionnaire}

As mentioned earlier, the objective of the second questionnaire was to compare students' liking of the two 
educational software programs; one based on narrative style and the other based on traditional (none narrative) style. The order of showing the two softwares to the students was balanced. Half of the students used the narrative software first then the traditional one. The other half used the opposite order. Table V shows that order of using the software did not influence results: mean ratings for the narrative vs. traditional software did not differ depending on the order given.

Therefore, in what follows, the order in which the software was used is ignored.

TABLE IV: DISTRIBUTION OF THE SAMPLE FOR THE RANKINGS OF EACH

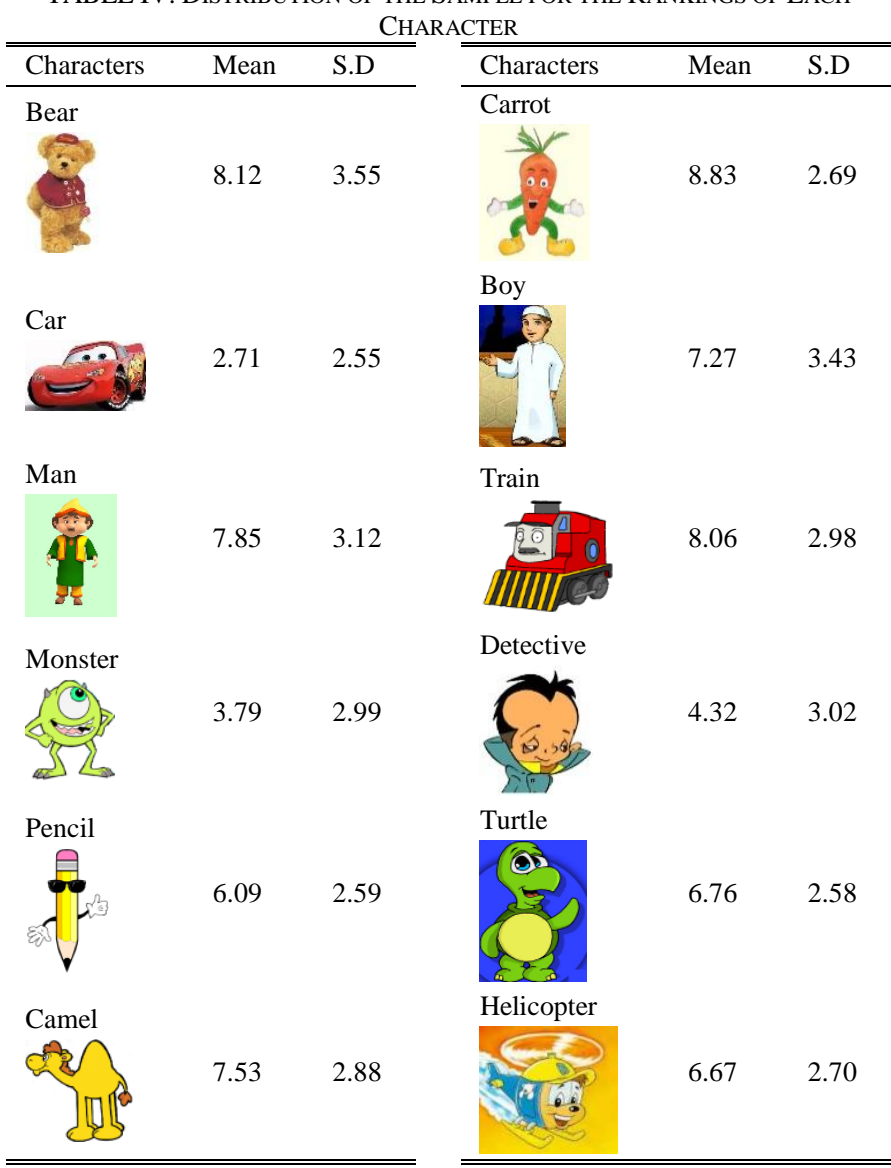

TABLE V: T-TeST to KNOW THE DIFFERENCES BETWEEN MEAN RATINGS OF THE SOFTWARE

\begin{tabular}{|c|c|c|c|c|}
\hline & \multicolumn{2}{|c|}{ Narrative style software } & \multicolumn{2}{|c|}{ Traditional style software } \\
\hline & $\begin{array}{l}\text { narrative } \\
\text { then } \\
\text { traditional } \\
\text { style }\end{array}$ & $\begin{array}{l}\text { traditional } \\
\text { then } \\
\text { narrative } \\
\text { style }\end{array}$ & $\begin{array}{l}\text { narrative } \\
\text { then } \\
\text { traditional } \\
\text { style }\end{array}$ & $\begin{array}{l}\text { traditional } \\
\text { then } \\
\text { narrative } \\
\text { style }\end{array}$ \\
\hline$N$ & 43 & 43 & 43 & 43 \\
\hline Mean & 4.19 & 4.15 & 3.41 & 3.22 \\
\hline S.D & 0.79 & 1.05 & 0.94 & 1.03 \\
\hline$t$ value & \multicolumn{2}{|c|}{0.231} & \multicolumn{2}{|c|}{0.914} \\
\hline Sig. & \multicolumn{2}{|c|}{0.81} & \multicolumn{2}{|c|}{0.36} \\
\hline
\end{tabular}

\section{B. Differences between the Samples According to Style}

To see if, overall, the narrative software was preferred over the traditional software, the mean ratings from all three questions were obtained. Independent samples t-test results in Table VI revealed that there is a highly significant difference between the software based on narrative style and the other one that based on traditional style, with $t=5.876$ and $p<0.05$. The mean difference was in favour of the "software based on narrative style".
TABLE VI: T-TeST to KNOW THE DIFFERENCES BETWEEN MEANS

\begin{tabular}{lccccc}
\hline \hline $\begin{array}{l}\text { The type of the software } \\
\text { Software program based }\end{array}$ & $N$ & Mean & SD & $\begin{array}{l}t \\
\text { value }\end{array}$ & Sig. \\
$\begin{array}{l}\text { on narrative style } \\
\begin{array}{l}\text { Software program based } \\
\text { on traditional style }\end{array}\end{array}$ & 86 & 3.17 & 0.93 & & \\
\hline \hline
\end{tabular}

\section{CONCLUSION}

A study was undertaken to explore the perceptions of sixth elementary grade students regarding the use of narrative and traditional educational software in learning English as a foreign language. Analysis of the results shows that the character and the kind of story in narrative educational software affect the students' engagement with the educational software. The paper found that the educational software based on the narrative style better facilitate students' engagement with the software comparing with educational software based on traditional style.

However, it may be more relevant and interesting to have two different versions of the software with different characters (one to suit the boys and another for girls). The characters could be chosen according to gender preferences by the users at the beginning of the software. Where it is not possible to have two characters, another suggestion would be to select a character which would suit both boys and girls. However, this method may not have the same result of using two different characters in engaging student interest. The same suggestions could be applied to the kind of story. Accordingly, further research is suggested to investigate more the students' perceptions taken into account gender differences.

\section{REFERENCES}

[1] L. Alkhateeb, "The guide in designing educational software for teachers," Irbid, Dar Alkindi, 1998.

[2] S. Macfarlane, G. Sim, and M. Horton, "Assessing usability and fun in educational software," presented at the 2005 Conference on Interaction Design and Children, Boulder, Colorado, ACM, 2005.

[3] B. Andrea, E. Chiara, C. Marcello, and B. Massimo, "Building 3D interactive environments for the children's narrative: A didactic project," presented at the 2005 ACM SIGCHI International Conference on Advances in Computer Entertainment Technology, Valencia, Spain, ACM, 2005.

[4] D. Squires, "Educational software and learning: Subversive use and volatile design," in Proc. the Thirty-Second Annual Hawaii International Conference on System Sciences, vol. 1, IEEE Computer Society, 1999.

[5] B. Min, "A study of the attitudes of Korean adults toward technology-assisted Instruction in English-language programs," Northern Illinois University, 1998.

[6] S. Almubireek, "Level of adoption of the internet by ESL teachers at the Ohio State University," 2001.

[7] Microsoft Press computer dictionary, The Comprehensive Standard for Business, School, Library, and Home, Redmond, Wash., Microsoft Press, 1994.

[8] M. Warschauer, "Computer-assisted language learning: An introduction," Multimedia Language Teaching, pp. 3-20, 1996.

[9] B. W. Mott, S. W. Mcquiggan, S. Lee et al., "Narrative-centered environments for guided exploratory learning," presented at the Agent Based Systems for Human Learning Workshop at the 5th International Joint Conference on Autonomous Agents and Multiagent Systems, 2006.

[10] S. Y. Salah, "The impact of a program based on story in the creative skills of reading among pupils in primary school," Studies in the Curricula and Teaching Methods, vol. 81, pp. 83-125, 2002. 
[11] N. R. Norrick, Conversational Narrative: Storytelling in Everyday Talk, Amsterdam, Philadelphia: J. Benjamins, 2000.

[12] J. xFraenkel and N. Wallen, How to Design \& Evaluate Research in Education, New York: McGraw-Hill, 2000.

Mohammed S. Alameer is a counsel at Ministry of Higher Education in Saudi Arabia. He obtained his master degree in information and communication technology from Griffith University in Australia. His research interest is focused on e-services especially in e-learning.
Thamer O. Alhussain is the dean of information technology at Saudi Electronic University (SEU). He is also an assistant professor in the Department of e-Commerce in SEU. Thamer obtained his master and $\mathrm{PhD}$ in information and communication technology from Griffith University in Australia. His current research interests include the success of information systems, acceptance and adoption of and $\mathrm{m}$-services, and the impact and measurement of LMS. 